\title{
Assessment of the cooperation activity in seed-corn production by contract farming: A case study at Phuoc Tan commune, Xuyen Moc district, Ba Ria Vung Tau province
}

\author{
Luan D. Tran*, Tho N. Vo, \& Giang T. Tran
}

Faculty of Economics, Nong Lam University, Ho Chi Minh City, Vietnam

ARTICLE INFO
Research Paper
Received: November 23, 2018
Revised: December 10, 2018
Accepted: December 21, 2018
Keywords
Contract farming
Enterprises and farmers linkage
Household farming economy
Seed-corn
Stakeholders

${ }^{*}$ Corresponding author

Tran Duc Luan

Email: luantd@hcmuaf.edu.vn

\begin{abstract}
This paper used the qualitative research, based on the analysis of multi-dimensional information from stakeholders to investigate the seed-corn production activity by the contracted farming at Phuoc Tan commune, Xuyen Moc district, Ba Ria Vung Tau province. The results showed that Thailand CP Company supported the farmers by sponsoring the seeding cost, providing technical support in production and buying the products. Farmers who participated in seed-corn production had a significantly higher income compared to those of other crops. In the collaboration contract, the company had terms and conditions to reserve its monopoly seed-corn product. Therefore, most of the farmers complied with the agreement of not selling the products to outsiders. The descriptive statistic data, using Likert scale, also showed that the farmers had a fairly high levels of satisfaction. This study also found that the better the market capacity of a company was, the higher the scale and sustainability of cooperative activities from farmers in Phuoc Tan commune was.
\end{abstract}

Cited as: Tran, L. D., Vo, T. N., \& Tran, G. T. (2019). Assessment of the cooperation activity in seed-corn production by contract farming: A case study at Phuoc Tan commune, Xuyen Moc district, Ba Ria Vung Tau province. The Journal of Agriculture and Development 18(2), 1-11. 


\title{
Đánh giá hoạt động hợp tác trồng bắp giống theo hình thức hợp đồng tại xã Phước Tân, huyện Xuyên Mộc, tỉnh Bà Rịa Vũng Tàu
}

\author{
Trần Đức Luân*, Võ Ngàn Thơ \& Trần Thanh Giang
}

Khoa Kinh Tế, Trường Đại Học Nông Lâm TP. Hồ Chí Minh, TP. Hồ Chí Minh

\section{THÔNG TIN BÀI BÁO}

\section{Bài báo khoa học}

Ngày nhận: 23/11/2018

Ngày chỉnh sửa: 10/12/2018

Ngày chấp nhận: 21/12/2018

\section{Từ khóa}

Bắp giống

Các bên liên quan

Canh tác theo hợp đồng

Kinh tế nông hộ

Liên kết công ty và nông hộ

*Tác giả liên hệ

Trần Đức Luân

Email: luantd@hcmuaf.edu.vn

\section{TÓM TẮT}

Bài viết này sử dụng phương pháp nghiên cứu định tính, trên cơ sở phân tích thông tin đa chiều từ các bên liên quan đến hoạt động hợp tác sản xuất bắp giống theo hình thức hợp đồng tại xã Phước Tân, huyện Xuyên Mộc, tỉnh Bà Rịa Vũng Tàu. Kết quả nghiên cứu cho thấy, Công ty TNHH Hạt Giống C.P Việt Nam hỗ trợ cho nông hộ hạt giống, hướng dẫn quy trình kỹ thuật sản xuất và bao tiêu sản phẩm. Nông hộ tham gia trồng bắp giống có thu nhập cao hơn đáng kể so với cây trồng khác. Trong hợp đồng canh tác, công ty có những điều khoản và ràng buộc để bảo vệ sản phẩm bắp giống độc quyền. Do đó, hầu hết nông hộ tuân thủ và không bán ra bên ngoài như họ thường thực hiện đối với các nông sản thương phẩm khác. Số liệu thống kê mô tả, dùng thang đo Likert, cho biết nông hộ đánh giá mức độ hài lòng khá cao khi hợp tác. Cuối cùng, nghiên cứu nhận thấy, một khi năng lực thị trường của công ty càng tốt thì quy mô hợp tác và tính bền vững của hoạt động trồng bắp giống với nông hộ xã Phước Tân càng đạt được.

\section{1. Đặt Vấn Đề}

Trên thế giới, canh tác nông nghiệp theo hình thức hợp đồng là một chủ đề thú vị và gây tranh cãi ít nhất từ những năm 1970 (Glover, 1984; Minot, 1986). Một số quan điểm cho rằng, các công ty ký hợp đồng để có chi phí rẻ, chuyển rủi ro sản xuất cho nông hộ và làm cho vấn đề bất bình đẳng nông thôn trầm trọng hơn (Little \& Watts, 1994). Tuy nhiên, các tác giả khác cho biết đây là hình thức giúp cho nông hộ kết nối thị trường và cải thiện thu nhập (Minot, 1986). Thu nhập từ sản xuất theo hợp đồng tăng đối với người tham gia (Little \& Watts, 1994). Theo (Miyata \& ctv., 2009), việc tham gia hợp đồng giúp nông hộ nhận được thu nhập cao so với nông hộ không tham gia có cùng đặc điểm sản xuất và kinh tế-xã hội. Trong nghiên cứu của Porter \& Phillips-Howard (1997), mặc dù có phát sinh một số vấn đề xã hội nhưng nông hộ ở Châu Phi có thu nhập tốt hơn khi tham gia hợp đồng. Trong một nghiên cứu khác về bò sữa ở Ấn Độ, Birthal \& ctv. (2005) đã tính tỷ suất lợi nhuận gộp cho nông hộ chăn nuôi bò sữa gần gấp đôi so với nông hộ chăn nuôi bò sữa độc lập. Ở Việt Nam, các nghiên cứu cho thấy hầu hết nông hộ khi tham gia hợp đồng đều đạt lợi ích nhất định so với các nông hộ hoạt động độc lập. Tran \& ctv. (2013) phát hiện nông hộ tham gia hợp đồng thì năng suất lúa cao hơn dù chi phí lao động cao hơn nông hộ tự do. Tương tự, Le \& ctv. (2016) nhận định các nông hộ tham gia hợp đồng trồng chè sẽ nâng cao năng suất, làm tăng doanh thu và các khoản giá trị tăng thêm nhờ nhận được những hỗ trợ tối đa từ công ty. Tuy nhiên, Nguyen \& Bac (2016) điều tra tại địa bàn Thái Nguyên và Phú Thọ phản bác quan điểm các hợp đồng nông nghiệp làm tăng thu nhập của các nông hộ trồng chè. Thay vào đó, hợp đồng chỉ giúp nông hộ trồng chè tiếp cận tín dụng, khắc phục các vấn đề về nguồn cung đầu vào, mở rộng cơ hội thị trường và tiếp cận kỹ thuật tiên tiến. Tran \& Ikuo (2012) phát hiện hình thức tiêu thụ 
nông sản theo hợp đồng ở Việt Nam cũng tương đồng như các nước khác nhưng vẫn còn những trở ngại như chế tài thực thi hợp đồng còn kém, giá cả nông sản biến động, lợi ích mà hợp đồng mang lại chưa đủ hấp dẫn cho các bên tham gia. Nghiên cứu của Le \& ctv. (2016) chứng minh có tình trạng nông hộ sẵn sàng bán sản phẩm chè cho các công ty chế biến khác dù đã ký kết hợp đồng với công ty ban đầu. Theo kết quả nghiên cứu của Le \& ctv. (2011) tại Sơn La về ngành chè và mía đường, đối với chè, doanh nghiệp giữ quyền chủ động nên số hợp đồng bị phá vỡ rất ít, còn ngành mía đường thì ngược lại, nông hộ giữ quyền chủ động, số hợp đồng bị phá vỡ nhiều. Do đó, để tìm kiếm thêm một minh chứng khoa học cho vấn đề hợp tác nông nghiệp theo hình thức hợp đồng, nhóm nghiên cứu đã tiến hành chọn địa bàn xã Phước Tân, huyện Xuyên Mộc, tỉnh Bà Rịa Vũng Tàu như là một trường hợp điển hình. Phước Tân là xã nông nghiệp, có diện tích tự nhiên 3.241 ha, 16.502 nhân khẩu, 3.559 hộ, 9 đơn vị ấp, tỷ lệ hộ nghèo $3,42 \%$ và xã đã đạt 4/19 tiêu chí nông thôn mới (PCPT, 2018). Từ cuối năm 2007, Công ty TNHH Hạt Giống C.P Việt Nam có vốn đầu tư của Thái Lan (gọi tắt là Công ty $\mathrm{CP}$ Thái Lan) bắt đầu hợp đồng trồng bắp giống với nông hộ tại xã Phước Tân cho đến nay. Vì thế, bài viết tập trung vào các mục tiêu sau: (1) mô tả lịch sử hợp tác và thực trạng trồng bắp giống tại xã Phước Tân; (2) phân tích các bên liên quan đến hoạt động hợp tác trồng bắp giống; (3) đánh giá hoạt động hợp tác trồng bắp giống bằng hình thức hợp đồng theo quan điểm các bên liên quan; (4) đề xuất định hướng hợp tác giữa công ty và nông hộ trong tương lai.

\section{Cơ Sở Lý Luận và Phương Pháp Nghiên Cứu}

Theo từ điển Việt Nam, hợp đồng là sự thỏa thuận, giao ước giữa hai hay nhiều bên, theo đó có các điều khoản quy định quyền lợi và nghĩa vụ của các bên tham gia. Nông dân có thể thỏa thuận với chủ đất để thuê đất sản xuất; nông dân có thể thỏa thuận với người cung ứng vật tư để mua phân bón, thuốc bảo vệ thực vật; hoặc thỏa thuận với người mua để bán nông sản. Các thỏa thuận này có thể được lập thành văn bản hoặc chỉ bằng lời nói. Theo điều 24 của Luật Thương mại năm 2005 về hình thức hợp đồng, hợp đồng mua bán hàng hóa được thể hiện bằng lời nói, bằng văn bản hoặc được xác lập bằng hành vi cụ thể (NAV, 2005). Trên thực tế, hình thức hợp đồng bằng lời nói hoặc bằng hành vi rất khó quản lý vì không có bằng chứng cụ thể. Do vậy, trong bài viết này, hợp đồng giữa các bên liên quan khi hợp tác trồng bắp giống đã được xác lập bằng văn bản nên rất thuận lợi cho nghiên cứu.

\subsection{Lý luận về canh tác nông nghiệp theo hợp đồng}

Trong nông nghiệp, canh tác theo hợp đồng là hình thức thỏa thuận giữa nông dân với các doanh nghiệp chế biến, kinh doanh, cung cấp các sản phẩm nông nghiệp dựa trên thỏa thuận giao nhận hàng hóa trong tương lai, theo đó giá cả được định trước (Charles \& Andrew, 2001). Còn theo quan điểm của Sykuta \& Parcell (2003) trích trong nghiên cứu của Bao (2008), nhóm tác giả này cho rằng canh tác nông nghiệp theo hợp đồng đó là việc đưa ra những điều khoản và luật lệ cho việc giao dịch nông sản, trong đó có quy định quyền lợi và trách nhiệm của các bên tham gia. Đối với hình thức sản xuất tự do, nông dân có thể bán các nông sản phẩm cho các thương lái, siêu thị, sàn giao dịch hay các chợ truyền thống với giá cả phản ánh theo cung cầu thị trường hiện tại. Trong khi đó, đối với sản xuất theo hợp đồng thì giá cả phản ánh lợi ích, rủi ro và quyền quyết định của người mua và người bán. Như vậy, giá được thỏa thuận phải đảm bảo người bán thu được lợi ích và người mua có thể mua hàng với mức giá chấp nhận được, cho dù khi thời điểm giao hàng, giá thị trường có thể tăng hoặc giảm so với giá thỏa thuận ban đầu. Charles \& Andrew (2001) đã phân hình thức hợp đồng thành 5 nhóm mô hình, bao gồm: Mô hình tập trung (the centralized model), mô hình trang trại hạt nhân (the nucleus estate model), mô hình phi chính thức (the informal model), mô hình đa thành phần (the multipartite model) và mô hình trung gian (the intermediary model). Bao (2008) trong nghiên cứu về sản xuất nông nghiệp theo hình thức hợp đồng đã đúc kết thực trạng và kinh nghiệm áp dụng ở Việt Nam thành bốn mô hình. Thứ nhất là mô hình tập trung là mô hình mà các doanh nghiệp trực tiếp ký hợp đồng với nông dân. Doanh nghiệp chịu trách nhiệm cung cấp yếu tố đầu vào, hướng dẫn quy trình kỹ thuật và giám sát thực hiện. Nông dân chịu trách nhiệm cung cấp nguồn lực đầu vào như đất đai, lao động, vốn,...để thực hiện sản xuất. Bản chất mô hình này chính là sản xuất theo hợp đồng gia công, lợi ích và rủi ro được chia sẻ giữa các bên nhưng quyền quyết định thuộc về doanh nghiệp. Thứ 
hai là mô hình trang trại hạt nhân, cũng giống như mô hình tập trung nhưng doanh nghiệp nắm quyền sở hữu đất đai. Bên nông hộ chỉ thực hiện hoạt động sản xuất tạo ra sản phẩm và bán lại cho doanh nghiệp. Thứ ba là mô hình đa chủ thể, ở Việt Nam thường gọi là các mô hình liên kết bốn nhà. Thứ tư là mô hình phi chính thức, đây là mô hình theo kiểu hợp đồng miệng, dựa theo cơ chế lòng tin giữa người mua và người bán. Như vậy, xét trường hợp nghiên cứu tại xã Phước Tân, hoạt động hợp tác trồng bắp giống đã đi theo mô hình tập trung.

\subsection{Lý luận về các bên liên quan}

Donaldson \& Preston (1995) cho rằng, các bên liên quan (stakeholders) là tất cả những cá nhân, tổ chức, nhóm có lợi ích liên quan bao hàm cả bên trong và bên ngoài của tổ chức. Theo đó, các đối tượng sẽ ảnh hưởng hay chịu ảnh hưởng từ các hành vi, trạng thái và chính sách của tổ chức. Một quan điểm khác của Freeman \& ctv. (2010) khi phân tích các bên liên quan trong vấn đề quản trị chiến lược của đơn vị kinh doanh cho rằng, các bên liên quan là bất kỳ tổ chức và cá nhân ảnh hưởng từ những mục tiêu của tổ chức đó. Shannon (2014) nhận thấy giới học thuật quan tâm đến việc phân tích các bên liên quan vì số lượng các trích dẫn có sử dụng cụm từ các bên liên quan tăng rất nhiều. Hầu hết các nghiên cứu về các bên liên quan đã diễn ra lĩnh vực quản trị doanh nghiệp, trách nhiệm xã hội của công ty và quản lý chiến lược. Trong phạm vi của bài này, nhóm tác giả sử dụng lý thuyết các bên liên quan để tập trung vào việc phân tích vai trò, trách nhiệm và quyền lợi của các bên khi tham gia hợp đồng nông nghiệp.

\subsection{Phương pháp nghiên cứu}

Bài viết sử dụng phương pháp nghiên cứu định tính, trên cơ sở phân tích quan điểm và ý kiến đánh giá của các bên liên quan đến hoạt động hợp tác. Các thông tin thứ cấp được thu thập bao gồm các báo cáo kinh tế xã hội hàng năm của xã Phước Tân, các bài nghiên cứu trong và ngoài nước liên quan đến hợp tác nông nghiệp theo hình thức hợp đồng. Thông tin sơ cấp được thu thập bằng phương pháp tham vấn các bên liên quan đến hoạt động hợp tác theo hệ thống các câu hỏi mở và bảng câu hỏi bán cấu trúc (semistructured questionnaire). Bên cạnh đó, nghiên cứu này còn sử dụng các công cụ đánh giá nông thôn có sự tham gia (Participatory Rural Appraisal) và điều tra hộ. Nhóm nghiên cứu cùng với cán bộ UBND xã và các trưởng/phó các ấp đã có buổi làm việc về cách lấy mẫu và cuối cùng phân thành ba nhóm hộ. Nhóm thứ nhất gồm 60 hộ trồng bắp giống trong năm qua, họ nhớ rõ thông tin định lượng về doanh thu, chi phí và thu nhập khi trồng bắp giống. Nhóm thứ hai gồm 30 hộ không trồng bắp giống trong năm qua nhưng đã từng trồng ở các năm trước. Mục đích của việc chọn các hộ này là xem xét họ đánh giá như thế nào về hoạt động hợp tác, đặc biệt là tìm hiểu lý do vì sao năm qua họ không được trồng. Nhóm thứ ba gồm 30 hộ chưa từng trồng bắp giống nhưng họ có đất thích hợp để trồng cây này. Như vậy, tổng số mẫu điều tra là 120 hộ và các hộ được chọn ngẫu nhiên theo từng nhóm. Các chỉ tiêu đánh giá hoạt động hợp tác được sử dụng trong bài viết bao gồm: (1) các chỉ tiêu tài chính như chi phí, thu nhập, lợi nhuận và tỷ suất thu nhập từ trồng bắp giống và có so sánh cây trồng khác; (2) các chỉ tiêu thang điểm đánh giá mức độ đồng ý/hài lòng của nông hộ khi trồng bắp giống, (3) các quan điểm đánh giá định tính của các bên liên quan về những điểm tích cực và tồn tại khi hợp tác.

\section{Kết Quả và Thảo Luận}

\subsection{Lịch sử hợp tác và quá trình triển khai trồng bắp giống tại xã Phước Tân}

Năm 1998, Công ty CP Thái Lan làm thủ tục đầu tư kinh doanh tại Việt Nam. Công ty lấy tên giao dịch là C.P Seeds VN, người đại diện pháp luật là ông Wara Rojsirisup. Cuối năm này, Công ty này đã chọn nơi đầu tiên là xã Tiên Thuận, huyện Bến Cầu, tỉnh Tây Ninh để hợp tác nồng hộ thực hiện mô hình trồng thí điểm 7 ha bắp giống, kết quả hạt giống có chất lượng tốt nên công ty mở rộng đến huyện Củ Chi (TP.HCM), huyện Trảng Bàng và huyện Bến Cầu (tỉnh Tây Ninh) với tổng diện tích gần 750 ha. Từ năm 2000 - 2006, công ty tiếp tục hợp tác với tỉnh Tây Ninh, Đồng Nai và Ninh Thuận bằng cách đưa các kỹ sư nông nghiệp đi khảo sát các vùng tiềm năng, khi thấy nơi nào thích hợp thì lên kế hoạch hợp tác với nơi đó. Đến cuối năm 2007 , công ty bắt đầu hợp tác với nông hộ ấp Tân Rú, xã Phước Tân để sản xuất bắp giống. Sự hợp tác này có được là nhờ sự vận động và lời mời của Cựu Bí thư Đảng ủy xã Phước Tân. Lúc đó, chính quyền UBND xã Phước Tân đã phổ biến thông tin xuống nông hộ, 
họp dân, nói rõ nội dung và yêu cầu của sự hợp tác và vận động nông hộ tham gia. Từ đó đến nay, công ty vẫn hợp tác với nông hộ xã Phước Tân để trồng bắp giống và vùng đất thích hợp trồng bắp giống tập trung là ấp Tân Rú, Núi Lá và Bà Rịa (Hình 1). Các ấp còn lại như Tân Trung và ấp Thạnh Sơn $2 \mathrm{~B}$ có đất thích hợp trồng bắp giống với quy mô diện tích nhỏ hơn. Lịch thời vụ trồng bắp giống đã được các kỹ sư nông nghiệp của công ty quyết định sau khi khảo sát và tham vấn người am hiểu về nông nghiệp ở xã này. Ngoài bắp giống, xã Phước Tân cũng có trồng lúa, đậu các loại và các cây lâu năm như tiêu và điều. Theo quá trình triển khai, lãnh đạo UBND xã đã phải can thiệp rất nhiều nhằm thúc đẩy sự hợp tác. Nhờ hai hợp đồng được ký kết, vấn đề hợp tác giữa các bên liên quan có tính pháp lý, có cơ sở để xử lý vi phạm nhằm đảm bảo tính thực thi.

Hợp đồng thứ nhất là hợp đồng quản lý gia công sản xuất bắp giống. Công ty $\mathrm{CP}$ Thái Lan đại diện cho bên $\mathrm{A}$ và Chủ tịch UBND xã Phước Tân đại diện cho bên $B$. Hợp đồng này nêu rõ trách nhiệm và quyền lợi của từng bên, các điều khoản và những cam kết thực hiện. Bên $\mathrm{B}$ chịu trách nhiệm quy hoạch vùng trồng và quản lý việc thực hiện của nông hộ.

Hợp đồng thứ hai là hợp đồng gia công sản xuất bắp giống. Công ty $\mathrm{CP}$ Thái Lan đại diện cho bên A, các trưởng ấp thay mặt danh sách những nông hộ tham gia đại diện cho bên $\mathrm{B}$. Hợp đồng này cũng quy định trách nhiệm và quyền lợi của hai bên. Đặc biệt là trong hợp đồng này có ghi rõ giá mua, các điều khoản tuân thủ nghiêm ngặt trong quy trình kỹ thuật sản xuất bắp giống.

Khi thu hoạch, công ty ấn định thời gian và đưa bao bì đựng sản phẩm, nông hộ tự tổ chức thu hái và tập kết bắp giống về một điểm gần vùng trồng, cán bộ thu mua của công ty sẽ cân trọng lượng và vận chuyển về nhà máy chế biến hạt giống của Công ty ở tỉnh Đồng Nai. Nhà máy này sẽ kiểm tra chất lượng sản phẩm và sẽ mua với các mức giá được quy định rõ trong hợp đồng gia công. Đại diện Công ty $\mathrm{CP}$ Thái Lan cho rằng, việc xác định giá mua bắp giống được công ty tính toán theo nguyên tắc đảm bảo nông hộ có thu nhập cao hơn các cây trồng khác.

\subsection{Các bên liên quan đến hoạt động hợp tác sản xuất bắp giống}

Các bên liên quan đến hoạt động hợp tác sản xuất bắp giống tại xã Phước Tân được tóm tắt ở
Hình 2 bao gồm: Công ty CP Thái Lan, nông hộ sản xuất bắp giống, UBND xã Phước Tân, Hội nông dân các cấp, Chi nhánh Ngân hàng Nông nghiệp và PTNT, Đại lý vật tư nông nghiệp trên địa bàn xã, Hội phụ nữ xã và các tổ chức xã hội khác. Hai bên cốt lõi trong hoạt động hợp tác đó chính là Công ty $\mathrm{CP}$ Thái Lan và các nông hộ tham gia trồng bắp giống. Trong suốt quá trình hợp tác, kỹ sư nông nghiệp của công ty thường xuyên hỗ trợ kỹ thuật, hướng dẫn và nhắc nhở nông hộ đảm bảo đúng quy trình sản xuất. Chính quyền UBND xã Phước Tân chịu trách nhiệm quy hoạch vùng sản xuất, tuyên truyền, vận động, quản lý, giám sát và xử lý các tình huống phát sinh. Thông qua công tác quản lý nhà nước, chính quyền UBND xã Phước Tân đã yêu cầu sự phối hợp từ tổ chức đoàn thể xã hội, trưởng/phó các ấp nhằm triển khai các hoạt động cụ thể và kế hoạch sản xuất bắp giống của công ty đến nông hộ. Nhìn chung, các nông hộ đánh giá cao vai trò của công ty, vì nếu không có công ty thì không thể hợp tác được. Ngoài ra, nông hộ còn cho rằng UBND xã Phước Tân có vai trò quan trọng việc vận động, giám sát tình hình thực hiện của các bên liên quan. Trường hợp, mối quan hệ mua bán dân sự giữa nông hộ và các đại lý vật tư nông nghiệp, vay tiền từ các tổ chức tín dụng chính thức. Cuối cùng là hội phụ nữ và các tổ chức khác cũng có liên quan nhưng mức độ đóng góp không đáng kể, họ chỉ vận động và phối hợp tổ chức họp dân.

\subsection{Phân tích dữ liệu điều tra nông hộ}

\subsection{1. Đặc điểm nông hộ và thực trạng trồng bắp giồng}

Trong 120 hộ điều tra thì có $68 \%$ số hộ có quy mô nhân khẩu từ 4 đến 5 người. Về số năm định cư, trên $96 \%$ nông hộ sống tại xã từ 15 năm trở lên. Ngoài ra, có 40\% số lượt hộ tham gia hội nông dân, $37 \%$ số lượt hộ tham gia hội phụ nữ và tỷ lệ còn lại tham gia các tổ chức khác. Về người quyết định chính trong nông nghiệp hầu hết có độ tuổi tập trung ở tuổi trung niên, nam giới chiếm $82 \%$, học vấn chủ yếu là cấp hai, chiếm $53 \%$. Các tài sản sản xuất nông nghiệp được đầu tư như máy bơm nước, hệ thống ống tưới, bình xịt thuốc bằng tay, bình xịt thuốc bằng máy, máy làm đất và các công cụ khác có giá trị nhỏ. Diện tích đất canh tác bình quân của hộ điều tra là 0,89 ha. Trong năm qua, hộ có thu nhập dưới 10 triệu đồng/tháng chiếm $77 \%$, từ 10 - 15 triệu đồng/tháng chiếm 

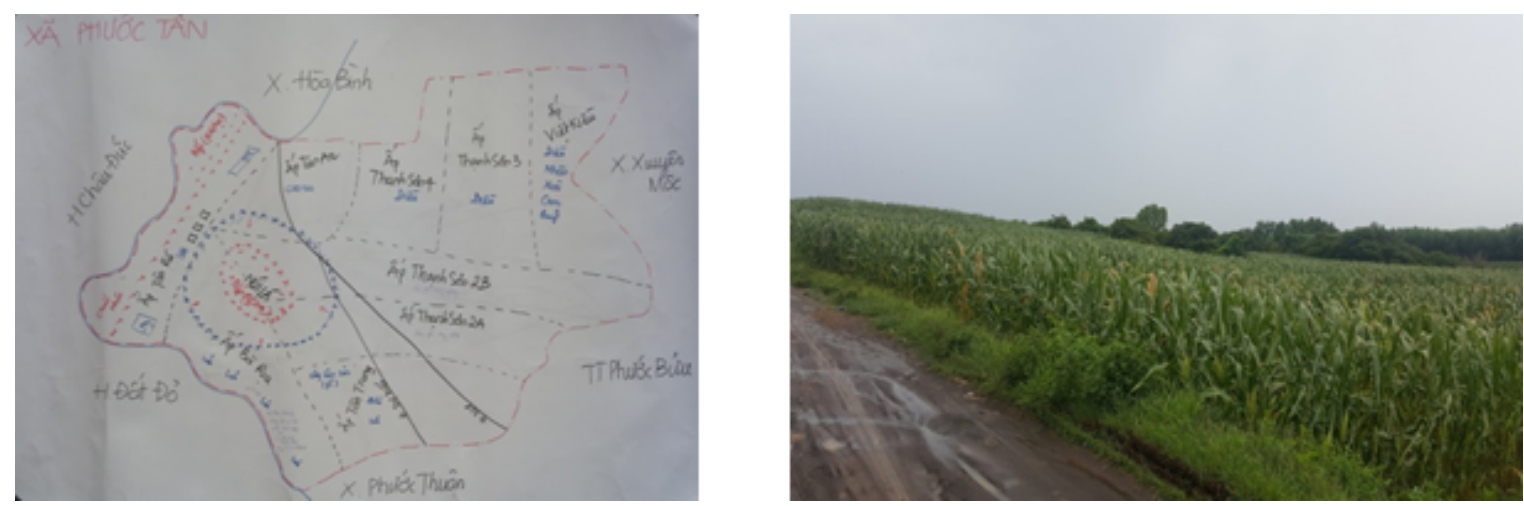

Hình 1. Vị trí sản xuất và hình ảnh bắp giống tại xã Phước Tân.

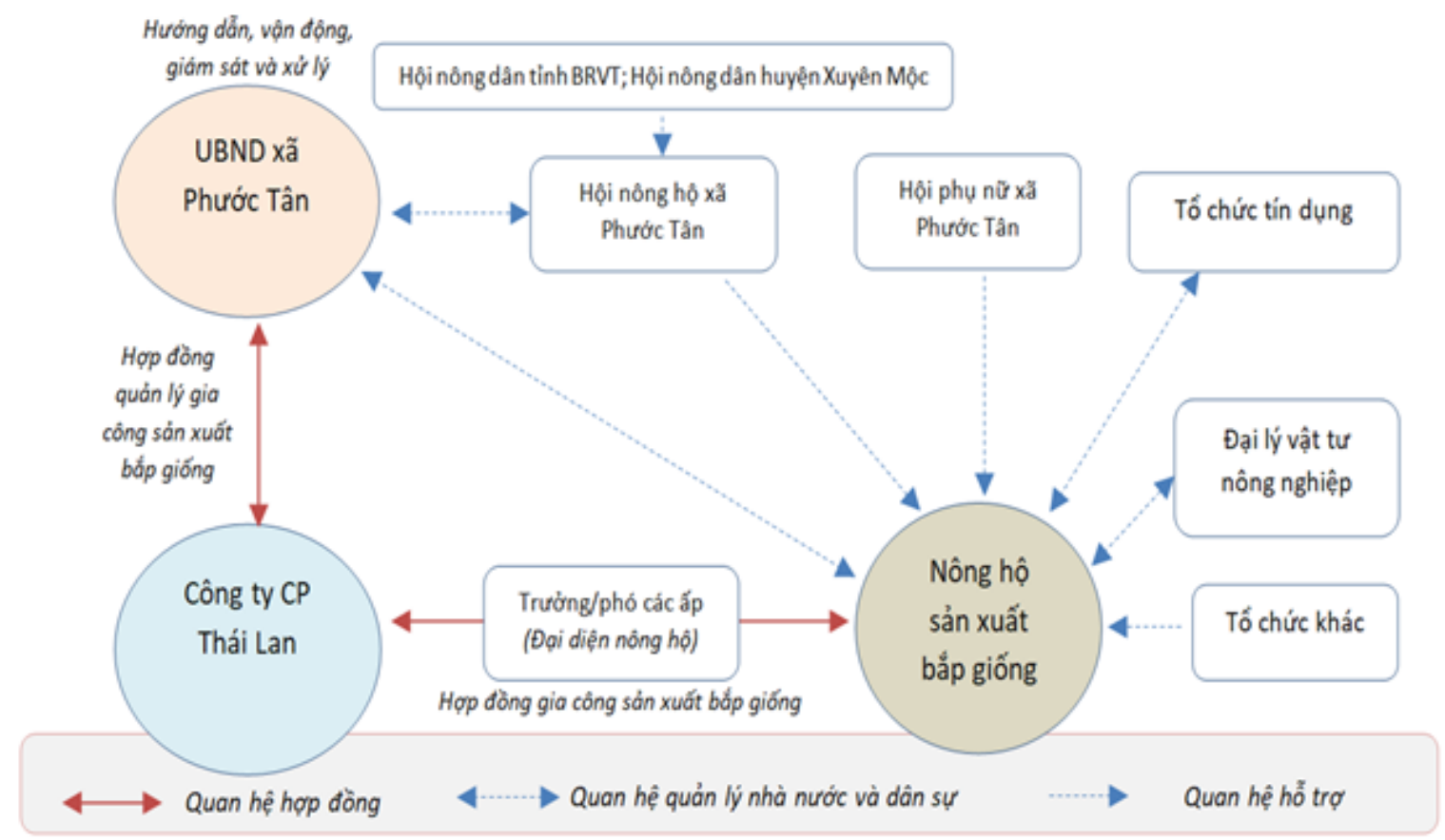

Hình 2. Các bên liên quan đến hoạt động hợp tác trồng bắp giống tại xã Phước Tân.

$17 \%$ và tỷ lệ còn lại là các hộ có thu nhập cao hơn. Nhìn chung, so sánh ba nhóm hộ, các nhóm này có đặc điểm nhân khẩu học gần tương đồng nhau.

Hiện nay, $100 \%$ các hộ nhóm 1 và 2 biết rõ thông tin trồng bắp giống. Trong khi đó, ở nhóm hộ 3 mặc dù chưa từng trồng bắp giống nhưng có đến $67 \%$ số hộ biết thông tin này. Các kênh cung cấp thông tin bao gồm chính quyền UBND xã Phước Tân, Công ty CP Thái Lan và nguồn khác. Trong số các nguồn đó thì nông hộ nhóm 1 và 2 tiếp nhận thông tin từ chính quyền xã là nhiều nhất, chiếm $60 \%$ tổng số lượt hộ tiếp nhận. Về hình thức, có $52 \%$ số lượt hộ nhận thông tin tại cuộc họp ở ấp/xã, $27 \%$ từ cán bộ và nông hộ khác nói lại, $17 \%$ từ loa phóng thanh và $4 \%$ từ hình thức khác.

Bảng 1 cho biết nhóm hộ 1 đương nhiên có 100\% số hộ trồng bắp giống năm qua vì theo tiêu chí chọn mẫu ban đầu, nhưng ở các niên vụ trước, tỷ lệ tham gia của nông hộ nhóm 1 dao động từ $20 \%$ đến $47 \%$. Trong khi đó, các nông hộ nhóm 2 không trồng bắp giống trong năm qua, nhưng các niên vụ còn lại có trồng, tỷ lệ dao động từ 
$23 \%$ đến $80 \%$. Trong suốt 9 niên vụ, ở Hình 3 chứng minh ở nhóm 1 có $15 \%$ số hộ trồng được 1 năm, $30 \%$ số hộ trồng 2 năm,... và trồng cả 9 năm chiếm $15 \%$ số hộ. Tương tự, nhóm hộ 2 cũng có sự biến động về tỷ lệ tham gia. Điều này chứng minh rằng, số nông hộ trồng bắp không ổn định trong những năm qua.

\subsubsection{So sánh kết quả và hiệu quả sản xuất bắp giống với cây trồng khác}

Trong năm qua, có 60 lượt hộ trồng bắp giống vụ 1, 14 lượt hộ trồng bắp giống vụ 2,32 lượt hộ trồng bắp thương phẩm, 22 lượt hộ trồng đậu xanh, 4 lượt hộ trồng lúa và 3 lượt hộ trồng hoa màu. Ngoài ra, các hộ điều tra còn trồng cây ăn trái, cây lấy gỗ và vườn tạp nên không được đề cập.

Ở Bảng 2, thu nhập từ bắp giống vụ 1 là 36,51 triệu đồng/ha và vụ 2 là 33,75 triệu đồng/ha. Tương tự, thu nhập từ bắp thương phẩm là 18,10 triệu đồng/ha/vụ, đậu xanh 22,82 triệu đồng/ha/vụ, lúa 21,58 triệu đồng/ha/vụ và rau màu là 27,83 triệu đồng/ha/vụ. Nếu xét từng vụ canh tác thì bắp giống đem lại thu nhập và tỷ suất thu nhập cao nhất. Tuy nhiên, nếu so sánh theo vòng đời sản xuất thì rau màu có thể trồng nhiều vụ trong năm, như thế kết quả và hiệu quả sẽ cao hơn cây bắp giống. Điều này là hoàn toàn có cơ sở, tuy nhiên tăng diện tích rau màu là một thách thức và bài học ở năm 2015, xã Phước Tân đã xảy ra tình trạng không tiêu thụ được sản phẩm. Ngoài ra, bài viết này có sử dụng phương pháp phân tích phương sai một yếu tố để so sánh sự khác biệt về giá trị trung bình của chỉ tiêu thu nhập của các cây trồng hàng năm với nhau. Với độ tin cậy $95 \%$, khi nông hộ trồng trên quy mô 1 ha, chỉ tiêu thu nhập của bắp giống với các loại bắp thương phẩm, đậu xanh và lúa thì có sự khác biệt do giá trị sig của các cặp cây trồng đó đều bé hơn mức ý nghĩa 0,05 . Như vậy, cây bắp giống vẫn chiếm ưu thế nếu xét về kết quả và hiệu quả sản xuất. Nếu công ty có năng lực mở rộng quy mô hợp tác thì xã Phước Tân có thể trồng bắp giống với diện tích đất canh tác lên đến 120 ha.

Một khía cạnh đánh giá khác được thực hiện thông qua việc nông hộ đánh giá các phát biểu theo thang đo 5 mức độ của Likert (Bảng 3). Hầu hết các hộ tham gia tự nguyện vì tỷ lệ cộng dồn cho thang điểm 4 và 5 là của nhóm hộ 1 là $96,7 \%$ và nhóm hộ 2 là $73,3 \%$. Như vậy, chỉ có số ít hộ bị bắt buộc trồng bắp giống theo các hộ khác. Các phát biểu 2 đến 9 bao gồm những đánh giá về sự nhất quán của công ty, chuyên môn các kỹ sư, bản hợp đồng, sự hỗ trợ của chính quyền ... . đều được các nông hộ nhóm 1 đánh giá cao do tỷ lệ cộng dồn của điểm 4 và 5 dành cho các phát biểu này dao động từ $70 \%$ đến $88,3 \%$. Tuy nhiên đối với nhóm hộ 2 thì chỉ dao động từ $43,3 \%$ đến $86,7 \%$. Nhìn chung, điểm của nhóm hộ 2 thấp hơn nhóm hộ 1 bởi vì họ không được trồng bắp trong năm qua nên có tâm lý nản lòng. Điểm mức độ hài lòng chung ở phát biểu 10 của các hộ nhóm 1 là 4,1 và các hộ nhóm 2 thì chỉ chấm ở mức 3,5 điểm.

\section{4. Đánh giá hoạt động hợp tác sản xuất bắp giống tại xã Phước Tân}

Những điểm tích cực của hoạt động hợp tác đó là Công ty $\mathrm{CP}$ Thái Lan có được sản phẩm tốt từ vùng nguyên liệu xã Phước Tân để đưa vào nhà máy chế biến hạt giống (Hình 4). Nông hộ trồng bắp giống có thu nhập cao hơn đáng kể so với cây hàng năm khác và yên tâm trong khâu tiêu thụ. Hoạt động hợp tác đã tạo việc làm không chỉ cho các nông hộ trực tiếp trồng bắp giống mà còn cho các lao động làm thuê trong nông nghiệp, các tổ chức tín dụng cho nông hộ vay vốn, các đại lý phân bón, thuốc trừ sâu và vật tư nông nghiệp cũng được tham gia cung ứng đầu vào. Nhờ có bắp giống mà mối quan hệ và sự gắn kêt giữa doanh nghiệp, nông hộ và chính quyền địa phương được gần gũi hơn thông qua các buổi họp, sản xuất ngoài đồng và giao lưu văn hóa thể thao. Bên cạnh đó, hoạt động trồng bắp giống còn tạo động lực kích thích các bên liên quan tìm kiếm thêm các mô hình hợp tác sản xuất cho cây trồng và vật nuôi khác. Thực tế các năm qua, diện tích gieo trồng vụ 1 là 90 ha/năm, vụ 2 là 60 ha/năm và cộng cho cả năm là 150 ha. Theo tính toán của nhóm nghiên cứu, hàng năm, tổng sản lượng bắp giống của cả xã là 1.221 tấn, giá trị tổng sản lượng là 8,19 tỷ đồng, tổng thu nhập cho các hộ trồng bắp giống là 5,31 tỷ đồng. Trong khi đó, nếu trồng bắp thương phẩm thì tổng thu nhập cho các hộ chỉ 2,72 tỷ đồng. Ngoài ra, công ty còn chi trả cho UBND xã Phước Tân tiền quản lý 30,53 triệu đồng/năm (định mức theo hợp đồng 25 đồng $/ \mathrm{kg}$ ) và đóng góp vào quỹ phúc lợi xã hội của xã với số tiền 24,42 triệu đồng/năm (định mức 20 đồng $/ \mathrm{kg}$ ). Như vậy, sản xuất bắp giống góp phần tạo việc làm, tăng thu nhập cho nông hộ và tạo nguồn thu cho địa phương.

Tuy nhiên, quá trình hợp tác cũng có những tồn tại (Hình 4), 46\% số nông hộ không chủ động 
Bảng 1. Tỷ lệ hộ trồng bắp giống ở từng niên vụ, 2008 - 2016

\begin{tabular}{cccccc}
\hline \multirow{2}{*}{ TT } & \multirow{2}{*}{ Niên vụ trồng } & \multicolumn{2}{c}{ Nhóm 1 (60 hộ) } & \multicolumn{2}{c}{ Nhóm 2 (30 hộ) } \\
\cline { 3 - 6 } & & Số hộ trồng (hộ) & Tỷ lệ hộ $(\%)$ & Số hộ trồng (hộ) & Tỷ lệ hộ $(\%)$ \\
\hline 1 & $2008-2009$ & 24 & 40 & 12 & 40 \\
2 & $2009-2010$ & 12 & 20 & 10 & 33 \\
3 & $2010-2011$ & 15 & 25 & 11 & 37 \\
4 & $2011-2012$ & 23 & 38 & 10 & 33 \\
5 & $2012-2013$ & 25 & 42 & 24 & 80 \\
6 & $2013-2014$ & 28 & 47 & 13 & 33 \\
7 & $2014-2015$ & 20 & 33 & 11 & 23 \\
8 & $2015-2016$ & 18 & 30 & 7 & - \\
9 & $2016-2017$ & 60 & 100 & - & \\
\hline
\end{tabular}

\section{Nhóm/Số năm}

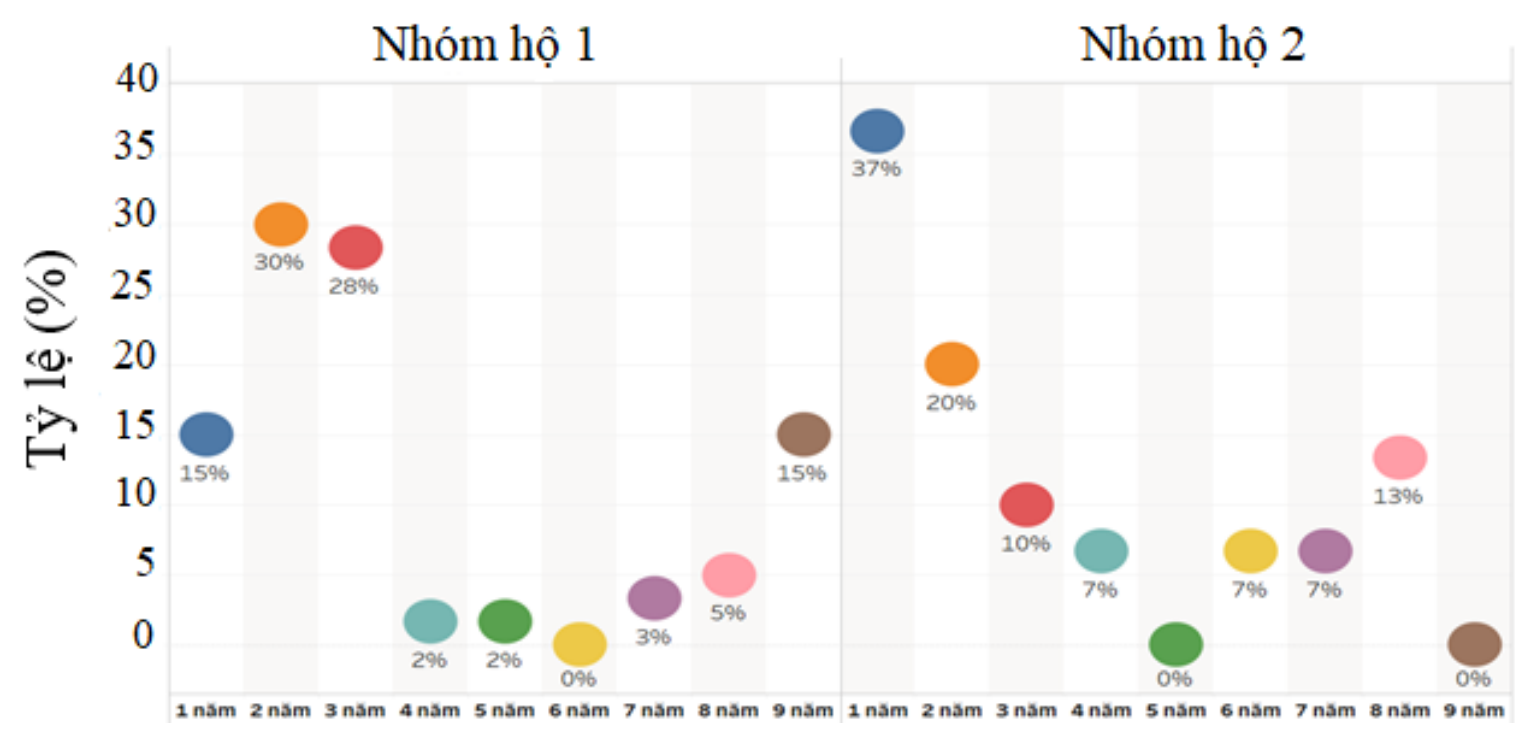

Hình 3. Tỷ lệ hộ phân theo số năm tích lũy trồng bắp giống, giai đoạn 2008 - 2016 .

được kế hoạch sản xuất bắp giống, trồng vụ này nhưng vụ tiếp theo thì không biết có được trồng hay không nên họ luôn có tâm lý chờ đợi thông báo; có $20 \%$ số hộ cho rằng quy trình trồng bắp giống phức tạp, $16 \%$ số hộ cho biết giá mua bắp giống do công ty ấn định chứ nông hộ không được tham gia thỏa thuận giá và có một số ý kiến phàn nàn công ty giao giống trễ, thanh toán chậm và khó liên lạc với kỹ sư của công ty khi cần.

\section{5. Định hướng hợp tác sản xuất giữa công ty và nông hộ trong tương lai}

Về dự định tương lai, có 97\% số hộ thuộc nhóm 1 có nhu cầu tiếp tục hợp tác, chỉ có $3 \%$ số hộ là không vì họ không có lao động. Ở nhóm hộ
2, do bị tạm dừng hợp tác trong năm qua nên tỷ lệ muốn hợp tác chỉ còn $67 \%$, các hộ còn lại không có nhu cầu vì đã chuyển sang trồng nhãn, chuối hoặc cây hàng năm khác. Đặc biệt, nhóm hộ 3 chưa được tham gia lần nào nhưng vẫn có $43 \%$ số hộ có nhu cầu hợp tác trồng bắp giống. Tuy nhiên, lãnh đạo UBND xã Phước Tân cho biết các hộ này mặc dù có đất thích hợp cho việc trồng bắp giống nhưng vì phân bố rãi rác và diện tích nhỏ lẻ nên khó có thể quy hoạch thành vùng sản xuất bắp giống tập trung theo yêu cầu kỹ thuật của công ty. Dựa trên cơ sở phân tích thực trạng hoạt động hợp tác trồng bắp giống và quan điểm đánh giá những mặt tích cực và những điểm còn tồn tại trong suốt nhiều năm hợp tác, nhóm nghiên cứu đề xuất ba nhóm định hướng. 
Bảng 2. Kết quả và hiệu quả sản xuất bình quân 1 ha các loại cây hàng năm của hộ điều tra

\begin{tabular}{lccccccc}
\hline Khoản mục & \multirow{2}{*}{ ĐVT } & $\begin{array}{c}\text { Bắp giống } \\
\text { vụ 1 }\end{array}$ & $\begin{array}{c}\text { Bắp giống } \\
\text { vụ 2 }\end{array}$ & $\begin{array}{c}\text { Bắp thương } \\
\text { phẩm }\end{array}$ & $\begin{array}{c}\text { Đậu } \\
\text { xanh }\end{array}$ & Lúa & $\begin{array}{c}\text { Rau } \\
\text { màu }\end{array}$ \\
\hline A. TỐNG CHI & triệu đ/ha & 23,30 & 25,93 & 17,95 & 19,72 & 17,42 & 25,87 \\
1. Giống & triệu đ/ha & 0,00 & 0,00 & 1,49 & 1,35 & 0,57 & 2,14 \\
2. Phân bón & triệu đ/ha & 6,13 & 7,08 & 4,27 & 3,52 & 5,39 & 4,39 \\
3. Thuốc BVTV & triệu đ/ha & 1,25 & 1,23 & 1,41 & 1,23 & 1,68 & 3,07 \\
4. Nhiên liệu & triệu đ/ha & 0,73 & 1,38 & 0,28 & 0,18 & 0,10 & 0,80 \\
5. Lao động nhà & triệu đ/ha & 5,30 & 5,02 & 6,26 & 6,42 & 4,84 & 11,00 \\
6. Lao động thuê & triệu đ/ha & 7,01 & 7,42 & 2,43 & 5,44 & 3,08 & 2,78 \\
7. Khấu hao & triệu đ/ha & 1,18 & 1,46 & 0,71 & 0,49 & 0,51 & 1,33 \\
8. Lãi vay & triệu đ/ha & 0,42 & 0,57 & 0,27 & 0,31 & 0,00 & 0,23 \\
9. Chi khác & triệu đ/ha & 1,28 & 1,78 & 0,83 & 0,78 & 1,25 & 0,13 \\
\hline B.TỔNG THU & triệu đ/ha & 54,51 & 54,66 & 29,79 & 36,12 & 34,16 & 42,70 \\
1. Sản lượng & tấn/ha & 8,16 & 8,11 & 6,68 & 1,47 & 6,93 & 4,27 \\
2. Giá bán & nghìn đ/kg & 6,68 & 6,74 & 4,46 & 24,57 & 4,93 & 10,00 \\
\hline C. KẾT QUẢ VÀ HIÊUU QUẢ & & & & & & \\
1. Thu nhập & triệu đ/ha & 36,51 & 33,75 & 18,10 & 22,82 & 21,58 & 27,83 \\
2. Lợi nhuận & triệu đ/ha & 31,21 & 28,73 & 11,84 & 16,40 & 16,74 & 16,83 \\
3. Tỷ suất TN/CP & lần & 1,57 & 1,30 & 1,01 & 1,16 & 1,24 & 1,08 \\
\hline
\end{tabular}

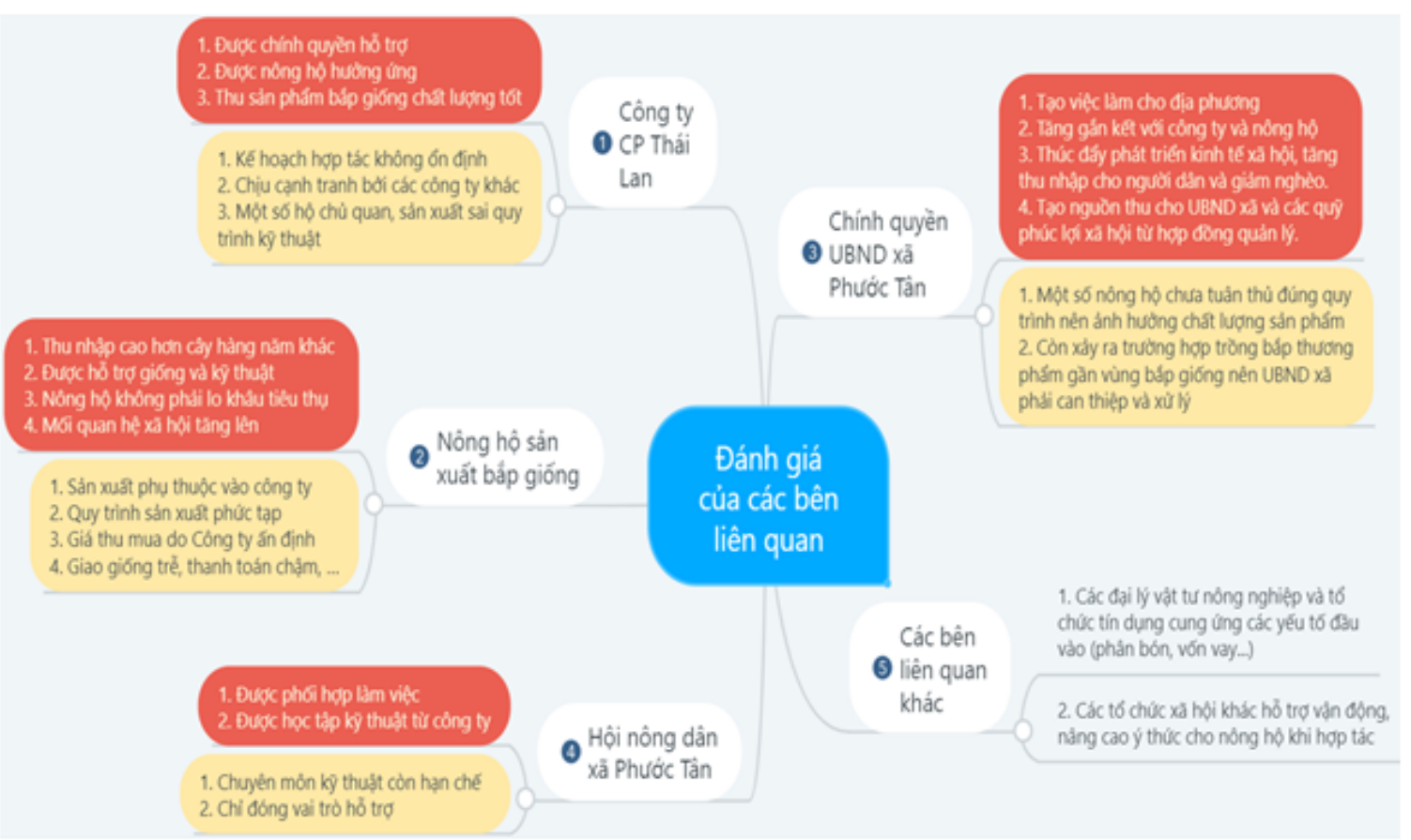

Hình 4. Tóm tắt quan điểm đánh giá của các bên liên quan về hoạt động hợp tác.

Thứ nhất, cần tăng cường hơn nữa vai trò của doanh nghiệp. Năng lực kinh doanh của công ty có ảnh hưởng nhất định đến vấn đề hợp tác. Do vậy, muốn có được sự hợp tác lâu dài, công ty cần đẩy mạnh chiến lược tìm kiếm thị trường đầu ra, cả thị trường trong nước và xuất khẩu, tạo lợi thế cạnh tranh hơn so với các doanh nghiệp kinh doanh cùng ngành khác. Khi có được thị trường 


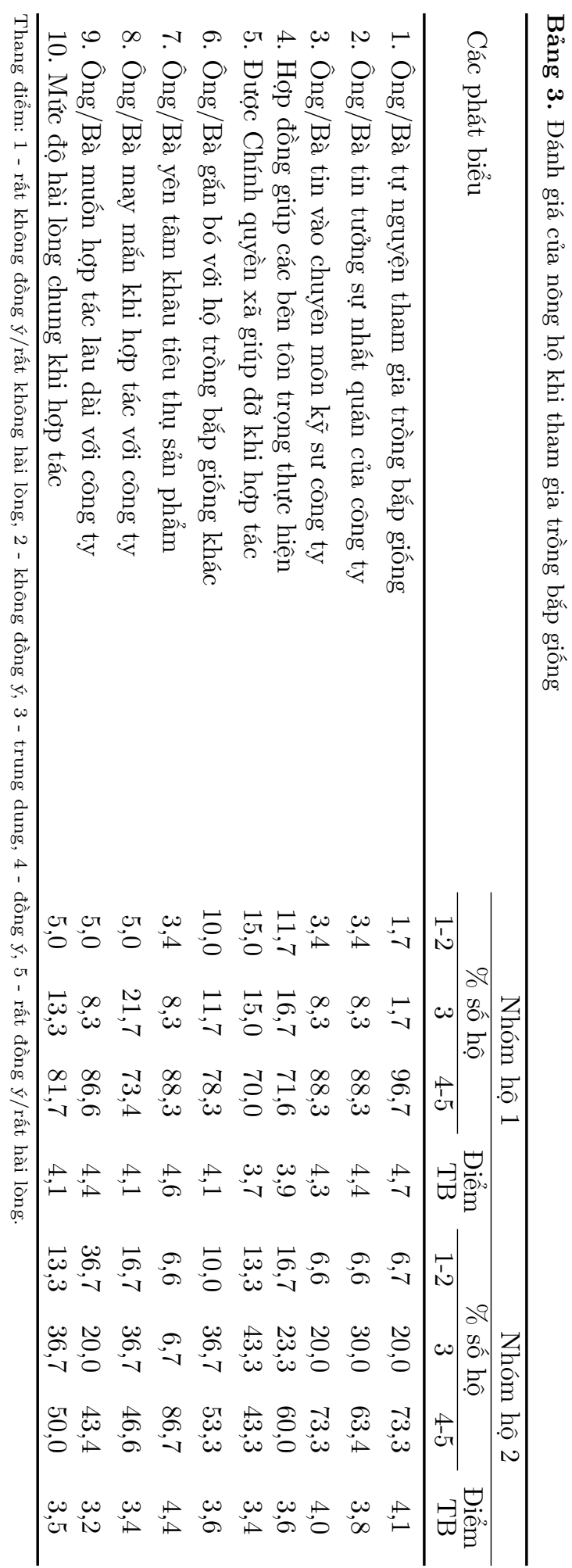

ổn định, công ty sẽ chủ động hơn trong việc triển khai các kế hoạch sản xuất đến nông dân. Công ty nên tiếp tục duy trì nguyên tắc đôi bên cùng có lợi và đảm bảo cho nông dân có thu nhập từ bắp cao hơn mặt bằng chung của các loại cây trồng khác, điều này chắc chắn sẽ tạo được động lực và sự hợp tác chặt chẽ hơn với nông dân.

Thứ hai, chú trọng vai trò và công tác quản lý của chính quyền địa phương. Trong thời gian qua, chính quyền UBND xã Phước Tân đã có vai trò tuyên truyền, vận động và giám sát sự tham gia của các bên liên quan đến hoạt động trồng bắp giống, đặc biệt là thường xuyên nhắc nhở các nông hộ đảm bảo sản xuất theo quy trình kỹ thuật của Công ty $\mathrm{CP}$ Thái Lan. Những việc này cần thiết được thực hiện lặp lại vào đầu mỗi vụ trồng bắp giống. Về công tác quản lý, chính quyền địa phương cần thúc đẩy và tăng cường hơn nữa sự phối hợp của các tổ chức đoàn thể địa phương, trong đó có hội nông dân xã, hội phụ nữ xã, các tổ chức tín dụng và các cán bộ ấp. Khi có mâu thuẫn giữa các bên liên quan thì chính quyền địa phương cần kịp thời hòa giải và xử lý để giảm tình trạng bất hợp tác trong sản xuất. Ngoài việc hợp tác với Công ty $\mathrm{CP}$ Thái Lan, chính quyền địa phương cần tăng cường hơn nữa sự năng động, kiến tạo, mời gọi các doanh nghiệp khác đến địa phương nghiên cứu và hợp tác sản xuất các nông sản mới.

Thứ ba là nâng cao nhận thức cho nông dân khi hợp tác với công ty. Rõ ràng là các nông hộ trồng bắp giống tại xã Phước Tân là thành phần được hưởng lợi nhiều nhất từ hoạt động này, do vậy họ cần phải có nhận thức cao khi hợp tác. Nông dân thường có quan niệm thích thì tham gia không thích thì không tham gia, sản xuất tự phát và áp dụng kỹ thuật theo kinh nghiệm. Do đó, chính quyền địa phương cần phải tuyên truyền và nâng cao nhận thức của nông dân. Sản xuất bắp giống phải tuân thủ theo quy trình, vì nếu làm không đúng thì ảnh hưởng đến năng suất, chất lượng hạt giống và cả thu nhập cho chính họ. Ngoài ra, vì là sản phẩm hạt giống nên vùng trồng bắp giống cần cách ly với vùng trồng bắp thương phẩm. Chính quyền địa phương cũng chú ý tuyên truyền cho các nông hộ không tham gia sản xuất bắp giống nên sản xuất các loại cây trồng khác, hoặc nếu có trồng bắp thương phẩm thì phải rãi vụ, không trùng vào thời điểm thụ phấn của vùng trồng bắp giống đã được địa phương quy hoạch. 


\section{Kết Luận}

Hợp tác nông nghiệp thông qua hợp đồng thực sự phát huy hiệu quả khi các bên liên quan đều được hưởng lợi, giữa công ty và nông hộ có sự ràng buộc và bình đẳng kinh tế; có sự phối hợp chặt chẽ với chính quyền địa phương trong quá trình triển khai thực hiện. Như vậy, kể từ năm 2007 đến nay, hoạt động hợp tác trồng bắp giống theo hình thức hợp đồng giữa Công ty $\mathrm{CP}$ Thái Lan và nông hộ xã Phước Tân đã chứng minh được sự thành công. Kết quả này có được là do sự nỗ lực của chính quyền địa phương, sự nhất quán theo nguyên tắc các bên đều có lợi của Công ty CP Thái Lan, sự phối hợp của các tổ chức đoàn thể địa phương, sự ủng hộ và tuân thủ hợp đồng của nông dân trồng bắp. Ngoài ra, nhờ vào tính đặc thù của sản phẩm, bắp giống độc quyền, giá thu mua tốt hơn bắp thương phẩm nên nông hộ chỉ bán cho Công ty CP Thái Lan chứ không có động cơ bán ra bên ngoài như các nông sản thương phẩm khác. Cuối cùng, nhóm nghiên cứu thấy được vai trò quan trọng của công ty, một khi năng lực phát triển thị trường của công ty càng tốt thì hoạt động hợp tác sản xuất bắp giống với nông hộ xã Phước Tân sẽ càng lâu bền hơn.

\section{Tài Liệu Tham Khảo (References)}

Bao, T. (2008). Developing contract farming systems in Vietnam. Journal of Economics and Management 22, 60-66.

Birthal, P. S., Joshi P. K., \& Ashok, G. (2005). Vertical coordination in high-value commodities (MTID Discussion Paper 85). International Food Policy Research Institute (IFPRI). Retrieved August 1, 2018, from http://ebrary.ifpri.org/utils/getfile/collection/p 15738coll2/id/74140/filename/74141.pdf.

Charles, E., \& Andrew, W. S. (2001). Contract farmingpartnerships for growth. FAO Agricultural Services Bulletin 145. Rome, Italy: FAO.

Donaldson, T., \& Preston, L. E. (1995). The stakeholder theory of the corporation: concepts, evidence, and implications. The Academy of Management Review 20(1), 65-91.

Freeman, R. E., Harrison, J. S., Wicks, A. C., Parmar, B., \& Colle, S. D. (2010). Stakeholder theory: The state of the art. London, England: Cambridge University Press.

Glover, D. J. (1984). Contract farming and smallholder outgrower schemes in less-developed countries. World Development 12(11-12), 1143-1157.
Le, A. H., Nguyen, A. Q., Nguyen, L. D., Hoang. H. T., \& Le, N. P. (2011). Processing enterprise-household farming contract models: case study on tea and sugar cane production in Son La Province. Journal of Science and Development 9(6), 1032-1040.

Le, O. T. K., Bui, N. T., \& Philippe, L. (2016). Tea production between contract and none contract farmers in Phu Tho province of Vietnam. Scholars Journal of Agriculture and Veterinary Sciences 3(2), 117-122.

Little, P. D., \& Watts, M. (1994). Living under contract: Contract farming and agrarian transformation in sub-Saharan Africa. Wisconsin, America: University of Wisconsin Press.

Minot, N. (1986). Contract farming and its effect on small farmers in less developed countries. Michigan, USA: Department of Agricultural, Food, and Resource Economics, Michigan State University.

Miyata, S., Minot, N., \& Hu, D. (2009). Impact of contract farming on income: linking small farmers, packers, and supermarkets in China. World Development 37(11), 1781-1790.

NAV (National Assembly of Vietnam). (2005). Commercial Law. Ho Chi Minh City, Vietnam: Labor and Social Publisher.

Nguyen, N. T. B., \& Bac, H. (2016). Comparative analysis of non-contract and contract farmers in tea sector in Vietnam: the case study in Thai Nguyen and Phu Tho provinces. Journal of Sciences and Technology 118(4), $47-53$.

PCPT (People's Committee of Phuoc Tan Commune). (2018). A report on the implementation of socialeconomic tasks in 2017. Ba Ria Vung Tau Vietnam: PCPT Office.

Porter, G., \& Phillips-Howard, K. (1997). Comparing contracts: an evaluation of contract farming schemes in Africa. World Development 25(2), 227-238.

Shannon, K. O. (2014). Environmental policy making and stakeholder collaboration: theory and practice. Florida, USA: CRC Press.

Singh, S. (2002). Contracting out solutions: Political economy of contract farming in the Indian Punjab. World development 30(9), 1621-1638.

Tran, N. Q., Ikuo, T., \& Hoang, D. V. (2013). Rice contract farming-the potential key to improve rice growers' income: a farm level study in An Giang province. Journal of Science and Development 11, 1062-1072.

Tran, N. Q., \& Ikuo, T. (2012). Analyzing causes of failure in contract farming enforcement between farmer and entrepreneur in Vietnam. Journal of Science and Development 7, 1069-1077. 